\title{
Alteration in the subcellular location of the inhibitor of growth protein p33(ING1b) in estrogen receptor alpha positive breast carcinoma cells
}

\author{
İmge KUNTER ${ }^{1}$, Emine KANDEMİs ${ }^{2}$, Hani ALOTAİBí ${ }^{3,4}$, Tülay CANDA ${ }^{5}$, Esra ERDAL BAĞRIYANIK ${ }^{2}$ * \\ ${ }^{1}$ Faculty of Pharmacy, Eastern Mediterranean University, Famagusta, North Cyprus via Mersin 10, Turkey \\ ${ }^{2}$ Department of Medical Biology and Genetics, Faculty of Medicine, Dokuz Eylül University, İzmir, Turkey \\ ${ }^{3}$ Department of Molecular Biology and Genetics, Faculty of Science, Bilkent University, Ankara, Turkey \\ ${ }^{4}$ Dokuz Eylül University, Advanced Biomedical Research Center, İzmir, Turkey \\ ${ }^{5}$ Department of Pathology, Faculty of Medicine, Dokuz Eylül University, İzmir, Turkey
}

\author{
Received: 06.03.2016
}

- $\quad$ Accepted/Published Online: 21.07.2016

- Final Version: 20.02 .2017

\begin{abstract}
ING1 has regulatory roles in the expression of genes associated with proliferation, apoptosis, and senescence. p33(ING1b) is the most widely expressed isoform of the gene. Downregulation of its nuclear expression is involved in differentiation and pathogenesis in invasive breast carcinoma. Yet the mechanism(s) by which p33 nuclear targeting is regulated remains unknown. In this study, we analyzed human invasive breast carcinoma tissue samples by immunostaining with p33 and correlating p33 location with the presence of ERa. Our findings show the expression of p33 protein in ERa-positive tumor samples was in the nucleus alone, while the expression was mainly in the cytoplasm in ERa-negative tumor samples. Examination of the localization of p33 in the nucleus and/or cytoplasm in several different cell lines demonstrated $17 \beta$-estradiol (E2) treatment causes dramatic compartmental shift in p33 protein from the cytoplasm to the nucleus in ER $\alpha$-positive MDA-66 cells. No significant differences in ER $\alpha$-negative MDA-MB-231 cells in the same conditions were observed. We show for the first time nuclear localization of p33 is regulated by estradiol induction in ERa-positive breast cancer cells. These results suggest compartmental shift in p33 by ER signaling may be an important molecular event in the differentiation and pathogenesis of invasive breast cancer.
\end{abstract}

Key words: p33(ING1b), estrogen receptor alpha, invasive breast carcinoma

\section{Introduction}

ING1 is a type II tumor suppressor that affects cell growth, apoptosis, and senescencebyaltering chromatin structure and regulates transcription (Garkavtsev et al., 1996; Russell et al., 2006; Coles and Jones, 2009; Li et al., 2011). The most widely expressed ING1 isoform is $\mathrm{p} 33$ (ING1b) and downregulation of nuclear p33(ING1b) expression was associated with more poorly differentiated tumors in invasive breast carcinoma (Nouman et al., 2003a). Furthermore, it has been shown that the transfer of $\mathrm{p} 33$ (ING1b) protein from the nucleus to the cytoplasm may result in the loss of normal cellular function of the protein. This might play a role in tumorigenesis and lymph node metastasis of oral squamous cell carcinomas as well as esophageal squamous cell carcinoma (Zhang et al., 2008; Zhu et al., 2012). Several studies showed that nuclear import of p33(ING1b) occurs concomitantly with physical and/or functional interactions with a subset of nuclear proteins, including $\mathrm{p} 53$, $\mathrm{p} 300 / \mathrm{CBP}$, and $\mathrm{HDAC} 1$ in different models. However, little is known about the way and the importance of nuclear localization (Feng et al., 2002; Kataoka

*Correspondence: esra.erdal@deu.edu.tr et al., 2003; Nouman et al., 2003b). p33(ING1b) may also have a role in estrogen-dependent signaling in mammalian cells. It was shown that p33(ING1b) interacts directly with the activation function 2 (AF2) domain of estrogen receptor $\alpha(E R \alpha)$ and modulates the transcriptional activity of an E2responsive reporter construct in a dose-dependent manner as well (Toyama et al., 2003). ING1 might help and/or contribute to the regulation of ERa-dependent target gene expression through the facilitation of a localized relaxation in chromatin compaction surrounding ERa-responsive genes and it might have a role in the development of breast cancers (Margueron et al., 2004; Doyon et al., 2006).

Therefore, it is critical to explain how the nuclear export of p33(ING1b) is regulated in ER signaling.

In the present study, we firstly demonstrated an abundant nuclear localization of p33(ING1b) in ERa expressing human invasive breast carcinoma tissues. Then we showed $17 \beta$-estrodiol (E2) induction enhanced localization of p33(ING1b) into the nucleus in ER a-positive breast cancer cell lines in vitro. 


\section{Materials and methods}

\subsection{Cell lines and culture}

Human breast adenocarcinoma cell lines, MDA-MB-231 (ER $\alpha$ negative) and MDA-66 (ER $\alpha$-positive), were used in this study. MDA-66 was produced by stable transfection of MDA-MB-231 with human ER expression vector (pCMV$\mathrm{ER} \alpha$ ) (Alotaibi et al., 2006).

Both cell lines were maintained in high glucose Dulbecco's modified Eagle's medium [Gibco, (CA, USA) supplemented with $10 \%$ fetal bovine serum (FBS), $1 \%$ penicillin/streptomycin (P/S), and $1 \%$ L-glutamine (Biochrom, Berlin, Germany)] at $37{ }^{\circ} \mathrm{C}$ in a $5 \% \mathrm{CO}_{2}$ incubator. MDA- 66 was maintained in the above medium with the addition of $0.4 \mathrm{mg} / \mathrm{mL}$ hygromycin (Roche, Penzberg Germany). In general, hormone induction experiments were performed in sf-DMEM (a phenol red-free DMEM supplemented with $10 \%$ dextran-coatedcharcoal stripped $\mathrm{FBS}, 1 \% \mathrm{P} / \mathrm{S}$, and $1 \%$ L-glutamine) unless otherwise mentioned. Two days before the addition of hormone, cells were fed with sf-DMEM in order to deplete the culture media from endogenous steroids and retinoids. E2 was applied to a final concentration of $10 \mathrm{nM}$ for $3 \mathrm{~h}$.

\subsection{Patients and tissues}

The patients studied comprised a series of 93 women with invasive breast carcinoma of mean age 54, ranging from 32 to 65 years. These patients were diagnosed at the Hospital of the Medical School of Dokuz Eylül University, İzmir, Turkey, between 1991 and 2006. Routinely processed, formalin fixed, paraffin wax embedded blocks were retrieved from the archives. The Ethics Committee of Dokuz Eylül University Medical School approved the study.

\subsection{Immunostaining}

Five-micrometer-thick sections from the paraffinembedded formalin-fixed blocks were used for immunostaining following deparaffinization with xylene/ alcohol and were subjected to antigen retrieval using a microwave in Tris-EDTA buffer (pH 8.0) for $20 \mathrm{~min}$. Mouse monoclonal anti-p33 (ING1b) antibody (Clone 15B9 produced by Dr R Çetin Atalay) was used with 1:5 dilution as followed in the Dako EnVision + Dual (DAKO, Denmark) method according to the manufacturer's instructions. This antibody has been tested for its specificity in different cell lines (Sayan et al., 2009). The signals were detected using diaminobenzidine (DAB) staining after the specimens were counterstained with hematoxylin. For the staining of adherent cells grown on coverslips, the same protocol starting with primary antibody incubation was followed after methanol fixation and blocking with 5\% fetal calf serum (FCS) in phosphate-buffered saline (PBS).
For immunofluorescence staining of cells grown on coverslips, cells were fixed by $4 \%$ paraformaldehyde (PFA) for $15 \mathrm{~min}$ and permeabilized using $0.25 \%$ Triton X-100 for $10 \mathrm{~min}$. Nonspecific protein binding was blocked by incubation with 10\% FCS for $30 \mathrm{~min}$ in PBS at room temperature (RT). Cells were then incubated with both mouse monoclonal anti-p33(ING1b) antibody (1:10) and rabbit polyclonal anti-ERa antibody (Millipore 06-935) (1:50) together in PBS containing $0.25 \%$ Triton X-100 (PBS-T) and $3 \% \mathrm{FCS}$ for $2 \mathrm{~h}$ at RT. After washing three times with PBS-T for $30 \mathrm{~min}$, cells were further incubated with goat anti-mouse IgG antibody, $(\mathrm{H}+\mathrm{L})$ FITC conjugated (Millipore AP124F) (1:2000) and goat anti-rabbit IgG antibody, rhodamine conjugated (Millipore AP132R) (1:2000) for $1 \mathrm{~h}$ at RT. Counterstaining was performed by DAPI staining (1:500) for $5 \mathrm{~min}$. After the slides were mounted using fluorescence-mounting medium (Dako), they were examined using an Olympus BX61 fluorescence microscope.

\subsection{Scoring}

The intensities of nuclear and cytoplasmic staining for p33ING1b on the cells were assessed on a four-point scale as follows: $(0)$ for $0 \%-25 \%$; (+) for $26 \%-50 \%$; (++) for $51 \%-75 \%$, and $(+++)$ for $76 \%-100 \%$. This scoring system was used for all proteins studied.

\subsection{Western blotting}

Cells were washed and scraped with ice-cold PBS on ice and centrifuged at $5000 \mathrm{rpm}$ for $5 \mathrm{~min}$. A ProteoJET Cytoplasmic and Nuclear Protein Extraction Kit (Fermentas K0311) was used to extract protein according to the manufacturer's instructions.

Protein concentration was determined by BCA assay under the manufacturer's instructions (Pierce 23225). The proteins were then resolved by sodium dodecyl sulfate polyacrylamide gel electrophoresis (SDS-PAGE) and transferred to PVDF membrane (Roche 03010040001, Mannheim Germany). The membrane was blocked with nonfat milk and immunoblotted with anti- p33(ING1b) antibody (1:100) and anti-ER $\alpha$ antibody (Millipore 06935) (1:500), separately. The unbound antibody was washed with TBS-T and the membrane was incubated with horseradish peroxidase-conjugated secondary antibody (Pierce 32430, 32460) and Super Signal West Dura Extended Duration Substrate (Pierce 34076) was used for detection. Mouse monoclonal anti-PCNA (PC10) antibody (Abcam ab29) (1:500) and rabbit polyclonal antiCalnexin (H-70) antibody (Santa Cruz-11397) (1:1000) were used as loading controls for nuclear and cytoplasmic fractions, respectively.

\subsection{Statistical analysis}

To assess the relations between nuclear and/or cytoplasmic p33ING1b and ERa expression in tumor tissues the chisquare statistical test was applied by using SPSS. 


\section{Results}

3.1. Subcellular expression of p33(ING1b) in invasive ductal breast carcinoma tissues

Ninety-three invasive breast carcinoma tissues were analyzed for the presence of ERa and for the localization of p33(ING1b). The tumor tissue series used in this study comprised 53 cases of invasive ductal carcinomas, 19 invasive lobular carcinomas, 9 medullary carcinomas, and 4 papillary, 5 metastatic, and 3 mucinous breast carcinomas.

Among the 93 cases studied, p33(ING1b) staining in either the nuclear or cytoplasmic part of the tumor was seen in 63 samples (68\%), while 29 out of the 93 samples (31\%) showed staining in both compartments. Only one case (1\%) did not show p33(INGb) staining in either the cytoplasm or in the nucleus. Figure 1 shows an example for strong p33(INGb) expression in the nucleus or cytoplasm of a tumor cell.

3.2. Increased nuclear expression of p33(ING1b) in estrogen receptor alpha positive breast carcinoma sections

In order to determine whether there is a correlation between p33(ING1b) localization and ERa expression,

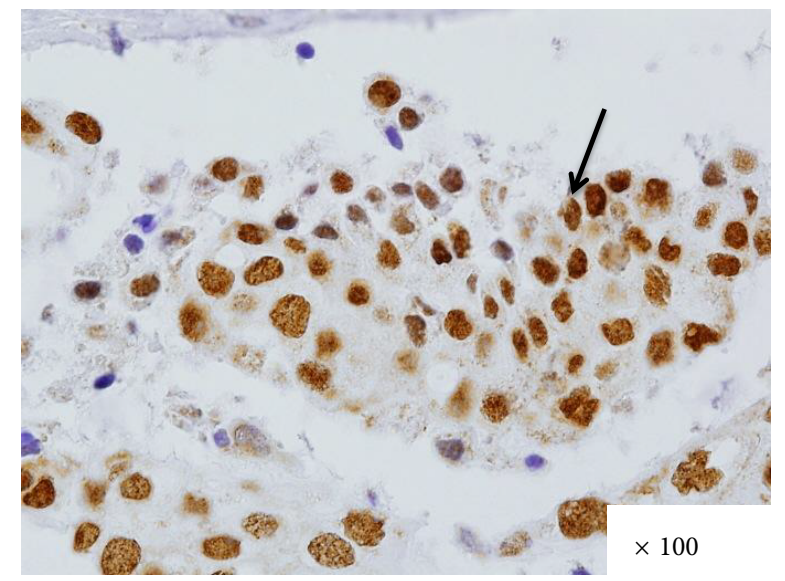

(A) subcellular localization of p33(ING1b) expression was compared between ERa-positive and ERa-negative breast tumor sections (Table 1). Based on immunohistochemical staining data, cytoplasmic expression of p33(ING1b) was statistically more evident in ERa-negative sections, while a striking shift to nuclear expression was observed in ER $\alpha$ expressing tumors. These results indicated that ERa expression in invasive breast carcinoma might influence a shift in the localization of p33(ING1b) towards the nucleus. Furthermore, when intensities of p33(ING1b) staining were analyzed in these tissues, no significance difference was observed (data not shown).

3.3. Estradiol activated ERa promotes nuclear localization of p33 (ING1b) in breast carcinoma cell line To further study the effect of ERa on the subcellular localization of p33(ING1b) in breast carcinoma cells, we carried out immunostaining experiments using p33(ING1b) antibody in MDA-MB-231, an ERa negative breast adenocarcinoma cell line, and its stable clone ectopically expressing ERa and MDA-66 cells. Under steroid-free conditions p33(ING1b) expression was more abundant in the cytoplasm of MDA-MB-231 as well as MDA-66 (Figure 2). However, treatment with $17 \beta$-estradiol

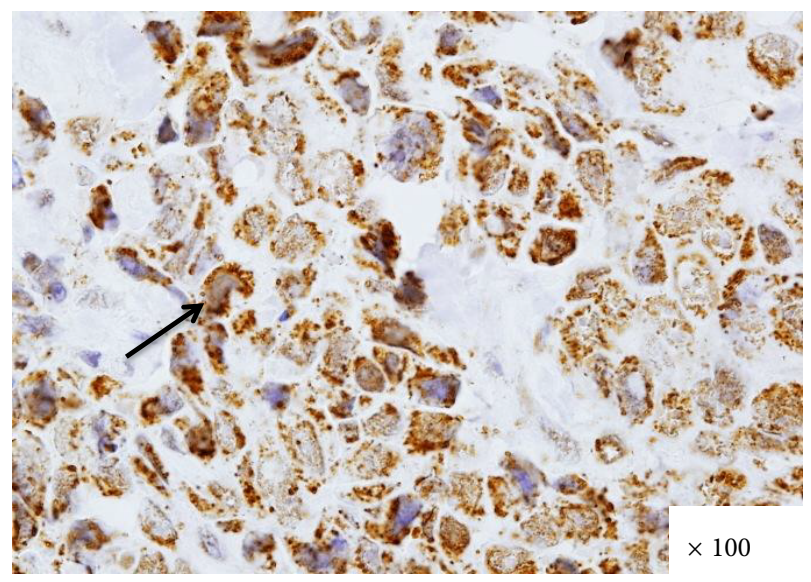

(B)

Figure 1. Positive p33(ING1b) immunohistochemical staining. (A) Invasive lobular breast carcinoma tissue strongly expressing p33(ING1b) only in the nuclei of tumor cells. (B) Invasive ductal breast carcinoma tissue strongly expressing p33(ING1b) in the cytoplasm of tumor cells.

Table 1. Relationship between compartmental p33(ING1b) expression and ERa expressions in invasive breast carcinoma.

\begin{tabular}{|l|l|l|}
\hline p33(ING1b) expression & ERa (-) (number of cases) & ERa (+) (number of cases) \\
\hline Only in cytoplasm & 22 & 10 \\
\hline In cytoplasm and nucleus & 13 & 16 \\
\hline Only in nucleus & 4 & 27 \\
\hline ND & 1 & - \\
\hline
\end{tabular}

${ }^{\star} \mathrm{P}<0.001, \mathrm{ND}=$ Not determined 
(E2) caused a significant increase in the percentage of cells with nuclear staining only in the ERa-expressing cells (MDA-66) compared to the ERa-negative ones (MDAMB-231) (Figure 2). We further analyzed approximately 300 cells in each condition to determine the percentage of cells expressing p33(ING1b) in the cytoplasm only, cytoplasm/nuclear, and nuclear only among the cells under estradiol induction as well as control in both cell lines. The results revealed that $17 \beta$-estradiol induction (E2) on ERa-positive cells caused a significant shift in p33(ING1) localization from the cytoplasm to the nucleus while it did not have an effect on the ERa negative cells (Table 2).

In order to analyze the changes in the subcellular localization of p33(ING1b) in the breast carcinoma cell lines under the effect of $17 \beta$-estradiol (E2) by using another method, we also performed immunoblotting analysis using nuclear and cytoplasmic cell extracts after E2 induction by the conditions described before in both MDA-MB-231 and MDA-66 cell lines. We found that $17 \beta$-estradiol (E2) induction caused increase in p33(ING1b) expression in nuclear lysate as well as a decrease in cytoplasmic lysate in an ERa-positive cell line, MDA-66. However, it did not significantly affect p33(ING1b) expression in both compartments of an ERa-negative cell line, MDA-MB-231 (Figure $3 \mathrm{~A}$ ). 17 $\beta$-Estradiol (E2) enhanced the expression of p33(ING1b) in the nuclear compartment 1.76-fold and decreased the expression of p33(ING1b) 20-fold in the cytoplasmic compartment (Figure 3B).

To evaluate the co-localization of both ER $\alpha$ and p33(ING1b) in the nucleus, immunofluorescence staining was carried out in MDA-66 cells under the effect of $17 \beta$-estradiol (E2). The number of ERa-positive cells

(A)
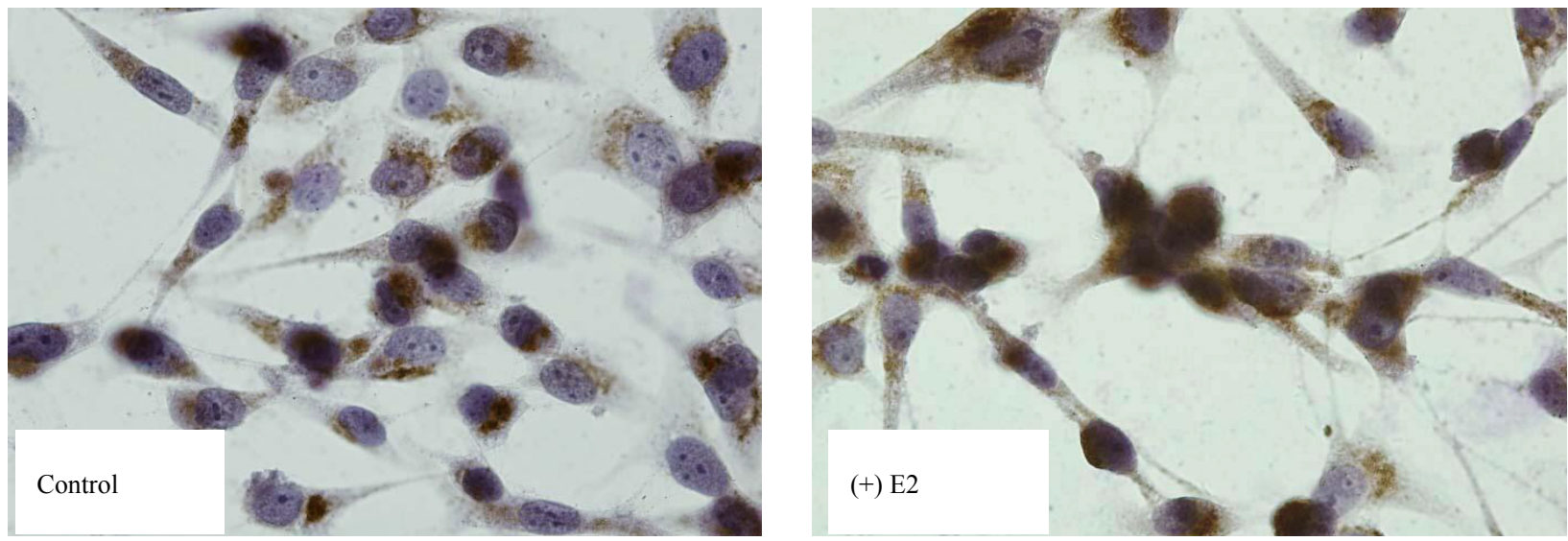

(B)

MDA - MB - 231
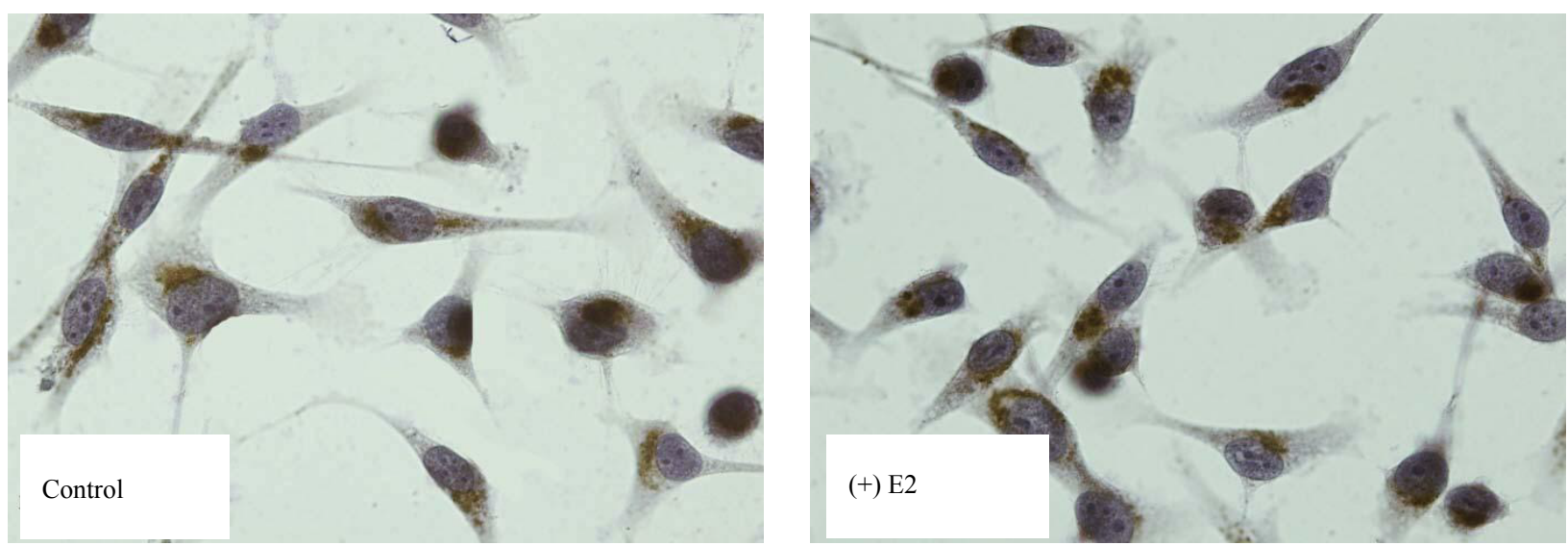

Figure 2. p33(ING1b) expression with 17 $\beta$-estradiol induction. (A) Nuclear staining of p33(ING1b) in ERa-positive MDA-66 cells. (B) Cytoplasmic staining of p33(ING1b) in ERa-negative MDA-MB-231 cells. (Experiments were carried out in triplicate. All figures have $40 \times$ magnification). 
KUNTER et al. / Turk J Biol

Table 2. Subcellular localization of p33(ING1b) expression with stable expression of ERa in MDA-MB-231 cells in ligand-dependent or nondependent manner.

\begin{tabular}{|l|l|l|l|l|}
\hline \multirow{2}{*}{} & \multicolumn{2}{l}{ ERa (-) cell } & \multicolumn{2}{l|}{ ERa $(+)$ cell } \\
\cline { 2 - 5 } & MDA-MB-231 & \multicolumn{2}{l|}{ MDA-66 } \\
\cline { 2 - 5 } & E2* (+) & E2 (-) & E2* (+) & E2 (-) \\
\hline p33(ING1b) positive (\%) & $24 \pm 2$ & $31 \pm 4$ & $10 \pm 2$ & $62 \pm 7$ \\
\hline Cytoplasmic & $71 \pm 4$ & $62 \pm 3$ & $61 \pm 4$ & $30 \pm 4$ \\
\hline Cyto./nuc. & $5 \pm 3$ & $5 \pm 2$ & $29 \pm 3$ & $2 \pm 1$ \\
\hline Nuclear & 0 & $2 \pm 2$ & 0 & $6 \pm 2$ \\
\hline p33(ING1b) negative (\%) & & & \\
\hline
\end{tabular}

* $10 \mathrm{nM} 17 \beta$-estradiol induction for $3 \mathrm{~h}$ in sf-DMEM medium

with p33(ING1b) in the nucleus and/or cytoplasm was analyzed (Figure 4A). After $17 \beta$-estradiol (E2) induction in the MDA-66 cell line, the number of cells with nuclear
p33(ING1b) increased 10-fold, while the number of cells with cytoplasmic p33(ING1b) did not change significantly (Figure 4B).

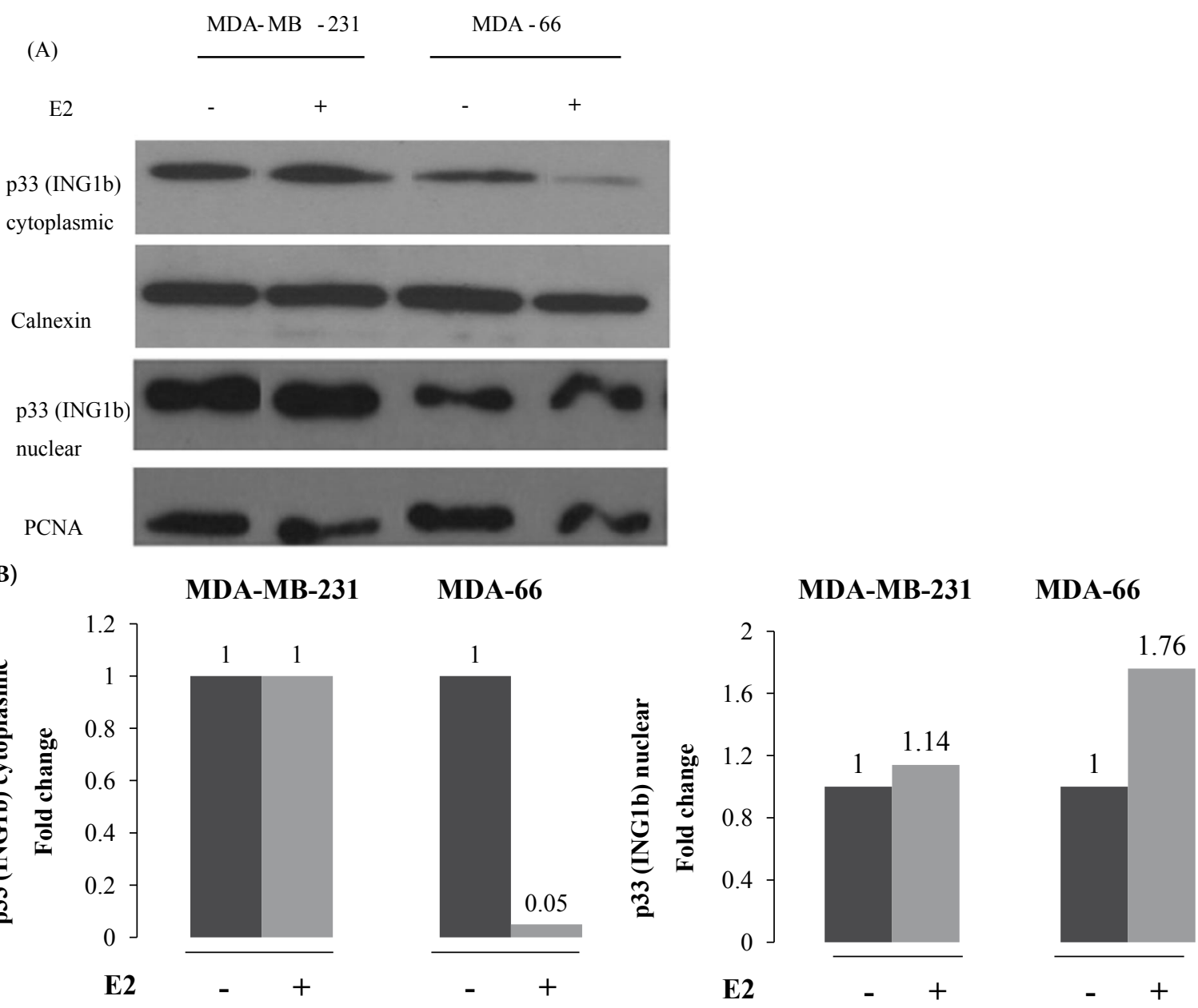

Figure 3. (A) Expression of p33(ING1b) in nuclear and cytoplasmic compartments of cells in both ERa-positive and ERanegative cell lines, MDA-MB-231 and MDA-66, respectively. (B) Density analysis of p33(ING1b) bands normalized with equal loading controls at both cytoplasmic and nuclear fraction. 
(A)
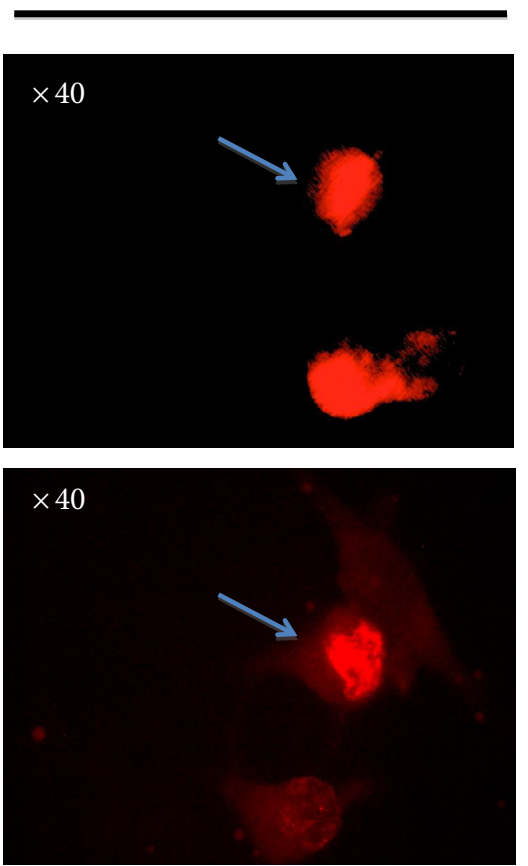

P33(ING1b)
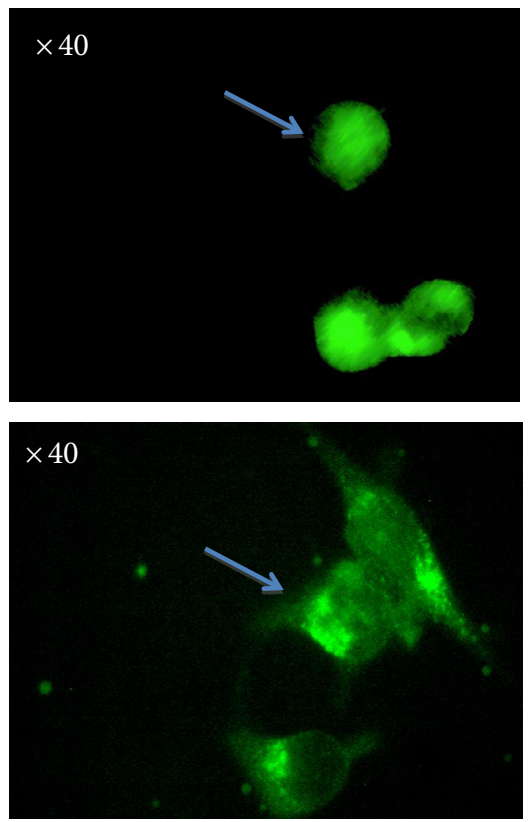

merge


(B)

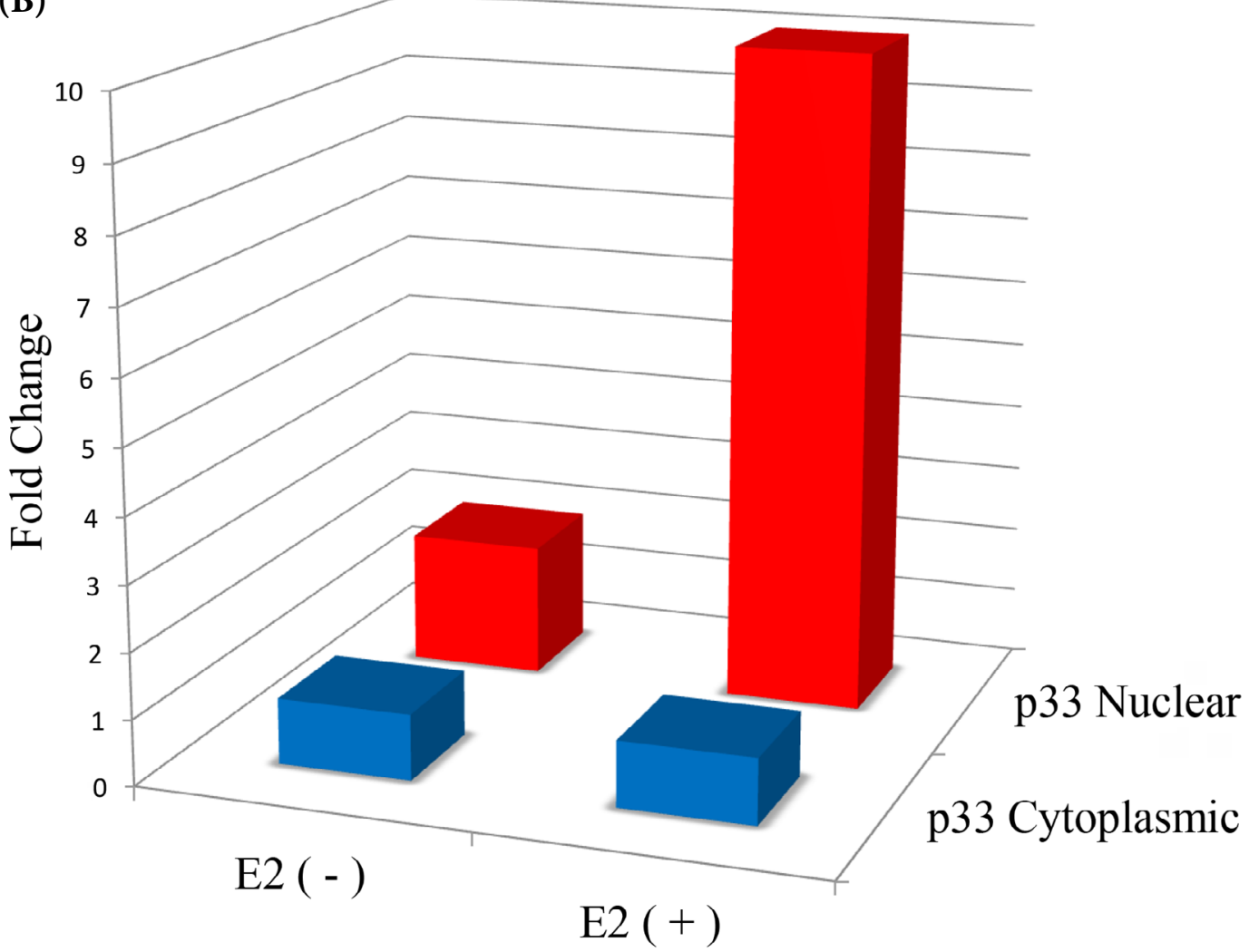

Figure 4. Co-localization of ERa and p33(ING1b) expression in MDA-66 cells. (A) Representative pictures for ERa and p33(ING1b) expression (upper line: arrows indicate the cells with both ERa and p33(ING1b) expression in nucleus; lower line: arrows indicate the cell with nuclear ERa and cytoplasmic p33(ING1b) expression). (B) Fold change in the number of cells with nuclear ERa having nuclear and/or cytoplasmic p33(ING1b) under the effect of 17ß-estrodiol (E2) induction of MDA-66 cells. 


\section{Discussion}

Although ING1 has initially been identified as a tumor suppressor gene, mutations in ING1 appear to be extremely rare in breast carcinomas, ovarian carcinomas, colorectal carcinomas, squamous cell carcinoma of different origins, and melanoma (Garkavtsev et al., 1996; Nouman et al., 2003b). Recently, the loss of nuclear ING expression has been described in several human cancers, suggesting that it may have a role in abrogation of ING function during carcinogenesis (Zhang et al., 2008; Nouman et al., 2002a, 2002b; Zhu et al., 2013). Nouman et al. showed that nuclear expression of p33(ING1b) was downregulated in invasive carcinoma of the breast and this alteration was significantly associated with more poorly differentiated tumors (Nouman et al., 2003a). They also reported a similar positive correlation between p33(ING1b) nuclear expression and ERa expression similar to what we have seen in the present study. This correlation is consistent with a function for nuclear ING proteins in directing towards a particular cellular fate under the effect of ERa signaling through interactions with functional proteins, such as HATs and HDACs. p33(ING1b) was shown to interact directly with the activation function 2 (AF2) domain of $\mathrm{ER} \alpha$ and to modulate the transcriptional activity of an ERa-responsive reporter construct in a dose-dependent manner (Toyama et al., 2003). This also indicates a role of nuclear p33(ING1b) in estrogen-responsive signaling in mammalian cells. Interestingly, ectopic expression of $\mathrm{p} 33$ (ING1b) protein in cancer cells has a function in DNA repair under DNA damage inducing stress in a p53-dependent or independent manner as in fibroblasts (Mobley and Brueggemeier, 2004; Kuo et al., 2007). It

\section{References}

Alotaibi H, Yaman EÇ, Demirpençe E, Tazebay UH (2006). Unliganded estrogen receptor- $\alpha$ activates transcription of the mammary gland $\mathrm{Na}+/ \mathrm{I}-$ symporter gene. Biochem Biophys Res Commun 345: 1487-1496.

Bianco NR, Perry G, Smith MA, Templeton DJ, Montano MM (2003). Functional implications of antiestrogen induction of quinone reductase: inhibition of estrogen-induced deoxyribonucleic acid damage. Mol Endocrinol 17: 1344-1355.

Coles AH, Jones SN (2009). The ING gene family in the regulation of cell growth and tumorigenesis. J Cell Physiol 218: 45-57.

Doyon Y, Cayrou C, Ullah M, Landry AJ, Coté, V, Selleck W, Lane WS, Tan S, Yang XJ, Coté J (2006). ING tumor suppressor proteins are critical regulators of chromatin acetylation required for genome expression and perpetuation. Mol Cell 21: 51-64.

Feng X, Hara Y, Riabowol K (2002). Different HATS of the ING1 gene family. Trends Cell Biol 12: 532-538. has also been shown that DNA damage is also induced by estrogen and/or estrogen metabolites with an ERdependent manner in breast carcinoma cell lines (Mobley and Brueggemeier, 2004; Bianco et al., 2016). Detoxifying enzyme activity markedly decreases with treatment with $17 \beta$-estradiol (E2) in MCF-7 cells (ER-positive), leading to increased susceptibility of cells to oxidative DNA damage. However, E2 has no effect on detoxifying enzyme activity in MDA-MB-231 (ER negative) cells (Iso et al., 2006). With regard to the established interval for E2 concentration in these reports, it is possible to conclude that $\mathrm{E} 2$ might cause DNA damage inducing stress in ERa-positive MDA-66 isogenic clone, but not in ERa negative MDA-MB-231; then $\mathrm{p} 33$ (ING1b) goes to the nucleus for its function in repair.

In the present study, we established a correlation between ERa expression and the nuclear localization of p33(ING1b) in a variety of breast cancers samples. We also clearly showed that nuclear localization of p33(ING1b) is regulated by $17 \beta$-estradiol (E2) in ERa-positive breast carcinoma cells. The mechanism demonstrated in the present study regarding the p33(INGb) protein shift from cytoplasm to nucleus in ERa-positive tumors in a hormone-mediated manner could help us to develop novel strategies for the diagnosis and treatment of invasive breast carcinomas.

\section{Acknowledgments}

We kindly thank Prof Frank Gannon and Assoc Prof Dr Rengül Çetin Atalay for providing us with MDAMB-231 and MDA-66 cell lines and p33(ING1b) antibody, respectively.

Garkavtsev I, Kazarov A, Gudkov A, Riabowol K (1996). Suppression of the novel growth inhibitor p33ING1 promotes neoplastic transformation. Nat Genet 14: 415-20.

Iso T, Watanabe T, Iwamoto T, Shimamoto A, Furuichi Y (2006). DNA damage caused by bisphenol A and estradiol through estrogenic activity. Biol Pharm Bull 29: 206-210.

Kataoka H, Bonnefin P, Vieyra D, Feng X, Hara Y, Miura Y, Joh T, Nakabayashi H, Vaziri H, Harris CC et al. (2003). ING1 represses transcription by direct DNA binding and through effects on p53. Cancer Res 63: 5785-5792.

Kuo WHW, Wang Y, Wong RPC, Campos EI, Li G (2007). The ING1b tumor suppressor facilitates nucleotide excision repair by promoting chromatin accessibility to XPA. Exp Cell Res 313: $1628-1638$.

Li N, Li Q, Cao X, Zhao G, Xue L, Tong T (2011). The tumor suppressor p33ING1b upregulates p16INK4a expression and induces cellular senescence. FEBS Lett 585: 3106-3112. 


\section{KUNTER et al. / Turk J Biol}

Margueron R, Duong V, Castet A, Cavaillès V (2004). Histone deacetylase inhibition and estrogen signalling in human breast cancer cells. Biochem Pharmacol 68: 1239-1246.

Mobley JA, Brueggemeier RW (2004). Estrogen receptor-mediated regulation of oxidative stress and DNA damage in breast cancer. Carcinogenesis 25: 3-9.

Nouman GS, Anderson JJ, Crosier S, Shrimankar J, Lunec J, Angus B (2003a). Downregulation of nuclear expression of the p33(ING1b) inhibitor of growth protein in invasive carcinoma of the breast. J Clin Pathol 56: 507-11.

Nouman GS, Anderson JJ, Lunec J, Angus B (2003b). The role of the tumour suppressor p33ING1b in human neoplasia. J Clin Pathol 56: 491-496.

Nouman GS, Anderson JJ, Mathers ME, Leonard N, Crosier S, Lunec J, Angus B (2002a). Nuclear to cytoplasmic compartment shift of the p33ING1b tumour suppressor protein is associated with malignancy in melanocytic lesions. Histopathology 40: 360366.

Nouman GS, Anderson JJ, Wood KM, Lunec J, Hall AG, Reid MM, Angus B (2002b). Loss of nuclear expression of the p33ING1b inhibitor of growth protein in childhood acute lymphoblastic leukaemia. J Clin Pathol 55: 596-601.
Russell M, Berardi P, Gong W, Riabowol K (2006). Grow-ING, AgeING and Die-ING: ING proteins link cancer, senescence and apoptosis. Exp Cell Res 312: 951-61.

Sayan B, Cevdet N, Emre T, Irmak MB (2009). Nuclear exclusion of p33ING1b tumor suppressor protein: explored in HCC cells using a new highly specific antibody. Hybridoma 28: 5-10.

Toyama T, Iwase H, Yamashita H, Hara Y, Sugiura H, Zhang Z, Fukai I, Miura Y, Riabowol K, Fujii Y (2003). p33ING1b stimulates the transcriptional activity of the estrogen receptor via its activation function (AF) 2 domain. J Steroid Biochem Mol Biol 87: 57-63.

Zhang JT, Wang DW, Li QX, Zhu ZL, Wang MW, Cui DS, Yang YH, Gu YX, Sun XF (2008). Nuclear to cytoplasmic shift of p33ING1b protein from normal oral mucosa to oral squamous cell carcinoma in relation to clinicopathological variables. J Cancer Res Clin Oncol 134: 421-426.

Zhu ZL, Yan BY, Zhang Y, Yang YH, Wang ZM, Zhang HZ, Wang MW, Zhang XH, Sun XF (2012). Cytoplasmic expression of p33ING1b is correlated with tumorigenesis and progression of human esophageal squamous cell carcinoma. Oncol Lett 5: 161-166. 